\title{
A Case of Ileus in a Patient with Schizophrenia Under Paliperidone Palmitate Treatment
}

\author{
Serdar Süleyman Can $^{1 凶}$ and Esra Kabadayı ${ }^{2}$ \\ ${ }^{1}$ Department of Psychiatry, Ankara Atatürk Training and Research Hospital, Ankara, Turkey \\ ${ }^{2}$ Department of Psychiatry, Yıldırım Beyazıt University, Ankara, Turkey
}

Constipation is a side effect of antipsychotic drugs that have high affinity for muscarinic cholinergic receptors. In addition, ileus is an important side effect of antipsychotic treatment, with potentially morbid and mortal consequences if early detection fails. In this report, a colonic ileus case is described in a patient with schizophrenia under the treatment of paliperidone palmitate. Consequently, complete physical examination and close screening of side effects are recommended when antipsychotics are prescribed.

Psychiatry Investig 2016;13(6):665-667

Key Words Ileus, Paliperidone palmitate, Schizophrenia.

\section{INTRODUCTION}

Constipation is a side effect of antipsychotic drugs that have high affinity for muscarinic cholinergic receptors. ${ }^{1}$ In some severe cases, constipation progresses to ileus and bowel ischemia, and causes multiple morbidity and motality related to sepsis and perforation especially among patients with schizophrenia. $^{2}$

In this report, a colonic ileus case is described in a patient diagnosed with schizophrenia under the treatment of paliperidone palmitate.

\section{CASE}

A 38 years-old, single, unemployed man, graduated from primary school was brought to Ankara Ataturk Hospital psychiatry clinic by police in November, 2013. His relatives told about his problems as stucking at home, having weight loss, diminishing his self care skills and stacking the waste. His first symptoms had started in his twenties with waste storage, so-

Received: June 16, 2014 Revised: December 16, 2015

Accepted: January 13, 2016 Available online: June 1, 2016

$\triangle$ Correspondence: Serdar Süleyman Can, MD

Department of Psychiatry, Ankara Atatürk Training and Research Hospital, Bilkent 06800, Ankara, Turkey

Tel: +90-312 2912525, Fax: +90-312 2912525, E-mail: serdarsccan@yahoo.com (c) This is an Open Access article distributed under the terms of the Creative Commons Attribution Non-Commercial License (http://creativecommons.org/licenses/by$\mathrm{nc} / 3.0$ ) which permits unrestricted non-commercial use, distribution, and reproduction in any medium, provided the original work is properly cited. cial withdrawal when he was carrying out his military service. He was examined by a physician since he had some adjustment problems on his sixth month in military and was exempted with diagnosis of psychotic disorder. After returning from army, he kept on stucking at home and waste storage. Social participation and self care skills of the patient, who had no medical treatment, diminished for the last 6 years. He did not have a shower or bath and kept his hair, nail and beard growing. The patient stucking at home, kept on talking himself and cursing, having agressive behaviours, repetative gesture and body movements. The patient was referred to Bolu Mental Health Care Hospital accompanied by the police with the complains in question 2 years ago. Having been hospitalised for fortnight the patient took biperiden $5 \mathrm{mg} /$ day, haloperidole $10 \mathrm{mg} /$ day, then olanzapine $5 \mathrm{mg}$ /day added on his order. On his constipation complains during his hospitalisation, he was diagnosed as ileus during his examination. He was undergone sigmoid resection operation by general surgeons. After his discharge from the hospital, he continued his olanzapine $20 \mathrm{mg} /$ day for 6 months and then quited his treatment. Having applied for keratoconus treatment to opthalmology department, the patients rejected cornea transplantation and reffered to our department in October, 2013. The patient having weight loss, diminishing his self care and social skills, stacking the waste, having agressive behaviours, repetative gesture and body movements was brought to our department accompanied by the police. Paliperidone palmitate $150 \mathrm{mg}$ intramuscular and biperiden $2 \mathrm{mg} /$ day treatment was given to 
the patient and he was hospitalised for further treatment. He had keratoconus and sigmoid resection operation in his past medical history. He had no smoking, alcohol intake and substance use history. In his family history, his brother has schizophrenia, his sister has major depression and his father has Parkinson disease.

In his psychiatric examination, he seemed untidy and older than his age with poor self care, long hair,nair and beard and had little interest to interview with limited eye contact. He was conscious and oriented by time, place and person. His memory and attention was not evaluated properly, intellegence was clinically normal. He had affective blunting and less facial expression. He responded only to questions in a monotonous and slow manner. His abstract thinking and judgement were deficient. He had perseverations in thought flow and thought insertion and passive influenced delusions in his thought content. He had commentary auditory hallucinations, diminished psychomotor activity, retardation, avolution, stereotypical hand movements and hair pulling behaviour. He had loss of appetite, weight and poor insight. His physical examination was normal.

In his first admission, BPRS score was 52, SAPS and SANS scores were 51 and 108, Simpson Angus Extrapyramidal Side Effect Symptom Scale was 2. Vitamin $B_{12}$ deficiency was detected during routine blood tests and vitamin supply was given. In the brain magnetic resonance imaging, nonspecific gliotic lesions were detected on left central semioval level and left transverse sinus was reported as hypoplasic and in T2A phase hyperintense signal finding was interpreted as sinus venous thrombosis. Venous magnetic resonance angiography was applied to the patient at the recommendation of neurology department. Left sinus calibration was obtained thinner than normal and since there was blood flow in this venous system, these findings were reported as hypoplasic or recanalised left transverse sinus. No other recommendation was offered by neurology department.

With the diagnosis of schizophrenia, second dosage of paliperidone palmitate $100 \mathrm{mg}$ intramuscular treatment was given to the patient one week after first dosage. Flexion posture, diminished associated extremity movement and bilateral upper extremity rigidity were clinically obtained and biperiden $2 \mathrm{mg}$ /day treatment was continued. In his clinical follow up, since upper extremity rigidity was decreased and constipation complain was also started, biperiden dosage was decreased to $1 \mathrm{mg} /$ day. Due to the fact that the patient had constipation, naussia, vomiting, abdominal distention and colonic liquid-gas level finding in his abdominal x-ray graphy, he was councelled to the general surgery department. Colonic segments were observed extensively dilated in colonoscopic examination. The abdominal tomography result was report- ed as all colonic segments were extensively dilated up to rectosigmoid region and sudden restriction was observed in the rectosigmoid colonic lumen. Oral feeding of the patient and biperiden $1 \mathrm{mg} /$ day treatment were discontinued and intravenous parenteral nutrition and hidration was started for his stability. Having been planned of ileus operation, the patient was transferred to general surgery department with the diagnosis of sigmoid volvulus. His BPRS score was 30, SAPS and SANS scores were 22 and 74, Simpson Angus Extrapyramidal Side Effect Symptom Scale was 2 at the time of his transfer to the general surgery department. Loop ileostomy operation was performed and the patient was discharged after operation.

\section{DISCUSSION}

Antipsychotic agents have both peripheral and central anticholinergic side effects. While central side effects can cause impairement in cognitive function, peripheral side effects include dry mouth, constipation, urinary retention, dilated pupils, blurred vision, increased heart rate and decreased sweating. ${ }^{3}$ Atypical antipsychotics can vary in their anticholinergic strength. Clozapine is considered to have highest anticholinergic activity, while risperidone is considered to have minimal anticholinergic activity. It is said as paliperidone, the active metabolite of risperidone, has not been shown muscarinic cholinergic receptor affinity. ${ }^{5}$

Constipation associated with antipsychotic treatment is frequent and can lead to severe consequences. The mechanism behind medication-induced gastrointestinal hypomo-

Table 1. FDA ileus reports due to long acting risperidone ${ }^{6}$

\begin{tabular}{ll}
\hline Year & Case of ileus \\
2006 & 1 \\
2008 & 4 \\
2010 & 1 \\
2011 & 2 \\
2012 & 1 \\
Gender & \\
Female & $58.33 \%$ \\
Male & $41.67 \%$ \\
Age & \\
$40-49$ & $33.33 \%$ \\
$50-59$ & $66.67 \%$ \\
Time on risperidone consta when & \\
patients have paralytic ileus & \\
$0-1$ years & \\
1-2 years & \\
\hline FDA: Food and Drug Administration &
\end{tabular}

FDA: Food and Drug Administration 
tility is primarily mediated by antagonism of muscarinic anticholinergic activity. Serotonin (5HT) receptors are also involved in gastrointestinal system motility. 5HT3 antagonists and 5HT4 agonists are promising therapeutic agents for the treatment of dysmotility syndromes. Antipsychotic agents have multiple actions at various $5 \mathrm{HT}$ receptor subtypes, and this may be another mechanism for gastrointestinal system hypofunctioning. ${ }^{6}$ Another possible contributing factor is sedation due to histamine $\mathrm{H} 1$ receptor antagonism of antipsychotics and resulting physical inactivity.

In extreme cases constipation may progress to bowel obstruction and paralytic ileus. Schizophrenia and its treatment with antipsychotics could be accompanied with a higher discomfort or pain threshold, which could be a reason why schizophrenic patients report somatic complaints later or less frequently and this could lead to under-diagnosis of constipation and its complications. ${ }^{8}$ Next to these changes in the pain perception; older age, female sex, long term and higher dosage use of the antipsychotics were associated with an increased risk of ileus. ${ }^{1}$ Although there is low information about ileus due to long acting antipsychotics, Food and Drug Administration reports due to long acting risperidone can give an idea on the subject (Table 1).

Paliperidone is a relatively new antipsychotic agent approved for the treatment of schizophrenia. There is no published case of ileus or bowel obstruction under paliperidone treatment in the literature. Even if paliperidone, an agent with low anticholinergic activity was preferred for the treatment of our patient; changes of patient's toilet and bowel habit might have contributed to ileus clinic. Anticholinergic medication use for the extrapyramidal system side effects might also aggravate the severity of constipation.

In conclusion, ileus is an important side effect of antipsychotic treatment, with potentially morbid and mortal consequences if early detection fails. Complete physical examination and close screenining of side effects are recommended when antipsychotics are prescribed. In addition to this, preventive actions should be promoted and appropriate interventions should be provided when needed.

\section{REFERENCES}

1. Nielsen J, Meyer JM. Risk factors for ileus in patients with schizophrenia. Schizophr Bull 2012;38:592-598.

2. Peyrière H, Roux C, Ferard C, Deleau N, Kreft-Jais C, Hillaire-Buys D, et al. Antipsychotics-induced ischaemic colitis and gastrointestinal necrosis: a review of the French pharmacovigilance database. Pharmacoepidemiol Drug Saf 2009;18:948-955.

3. Talbott JA, Halesk E, Yudofsky SC. The American Psychiatric Press Textbook. Washington, DC: American Psychiatric Press, Inc; 1988.

4. Lieberman JA 3rd. Managing anticholinergic side effects. Prim Care Companion J Clin Psychiatry 2004;6(Suppl 2):20-23.

5. Stahl SM. Antipsychotic Agents. In: Stahl SM, Editor. Stahl's Essential Psychopharmacology Neuroscientific Basis And Practical Applications, Third Edition. New York, USA. Cambridge University Press; 2008. p.413.

6. Gershon MD. Review article: serotonin receptors and transportersroles in normal and abnormal gastrointestinal motility. Aliment Pharmacol Ther 2004;20(Suppl 7):3-14

7. Kroeze WK, Hufeisen SJ, Popadak BA, Renock SM, Steinberg S, Ernsberger $\mathrm{P}$, et al. H1-histamine receptor affinity predicts short-term weight gain for typical and atypical antipsychotic drugs. Neuropsychopharmacology 2003;8:519-526.

8. Guieu R, Samuélian JC, Coulouvrat H. Objective evaluation of pain perception in patients with schizophrenia. Br J Psychiatry 1994;164: 253-255. 